\title{
Gender Differences Influence Renal Injury in Cisplatin-Treated Rats: Biochemical Evaluation
}

\author{
Ibrahim Aydin • Mehmet Agilli • Fevzi Nuri Aydin
}

Received: 7 March 2014 / Accepted: 13 March 2014 / Published online: 25 March 2014

(C) Springer Science+Business Media New York 2014

In a recent issue of Biological Trace Element Research, we read with great interest the article by Erman et al. "Effect of Lycopene Against Cisplatin-Induced Acute Renal Injury in Rats: Organic Anion and Cation Transporters Evaluation" [1]. Authors aimed to investigate the possible protective effects of lycopene on the cisplatin-induced acute renal injury and gene expression levels of some receptors in kidney. They have report that lycopene may protect the kidneys against injury from cisplatin nephrotoxicity. This article is instructive in terms of showing the effect of lycopene on cisplatin-induced nephrotoxicity. However, we would like to make some comments with respect to the study design.

Cisplatin is an antineoplastic agent which is commonly used to treat some tumors, but its usage has been restricted because of nephrotoxicity. For this reason, studies are ongoing to find a protective agent against this adverse effect of cisplatin. An important issue that should be considered in these studies is animal's gender which has significant effects on cisplatin nephrotoxicity. Previous studies report that one of the agents which thought to increase the nephrotoxic effect of cisplatin is estrogen [2]. Nevertheless, experimental animals' gender has not been stated in their paper [1]. On the other hand, it is reported that lycopene has antiestrogenic activity in vitro [3].
In this instance, the effectiveness of lycopene application will be different in both female and male rats. If there is any gender differences in study groups, the results should be reinterpret. In order to eliminate confusion on this issue, the gender of experimental animals should be stated in the article.

In conclusion, the explanation of these concerns will certainly provide the clearer information for the readers.

All other authors have read the manuscript and have agreed to submit it in its current form for consideration for publication in the Journal.

\section{References}

1. Erman F, Tuzcu M, Orhan C et al (2014) Effect of lycopene against cisplatin-induced acute renal injury in rats: organic anion and cation transporters evaluation. Biol Trace Elem Res. doi: 10.1007/s12011014-9914-x

2. Pezeshki Z, Nematbakhsh M, Nasri H et al (2013) Evidence against protective role of sex hormone estrogen in cisplatin-induced nephrotoxicity in ovariectomized rat model. Toxicol Int 20(1):43-47

3. Hirsch KI, Atzmon A, Danilenko M et al (2007) Lycopene and other carotenoids inhibit estrogenic activity of 17 beta-estradiol and genistein in cancer cells. Breast Cancer Res Treat 104(2):221-230

\footnotetext{
I. $\operatorname{Aydin}(\bowtie)$

Department of Biochemistry, Sarikamis Military Hospital, Sarikamis, Kars, Turkey

e-mail: mdiaydin@hotmail.com

M. Agilli

Department of Biochemistry, Agri Military Hospital, Agri, Turkey

F. N. Aydin

Department of Biochemistry, Sirnak Military Hospital, Sirnak,

Turkey
} 